\title{
Development of Maze Game on Interactive Whiteboard for Fine Motor Learning
}

\author{
Yerry Soepriyanto ${ }^{\text {a }}$ Akhmad Fakharuddin ${ }^{\mathrm{a}}$, Sihkabuden $^{\mathrm{a}}$, Eka Pramono Adi ${ }^{\mathrm{a}}$ \\ ${ }^{a}$ Educational Technology, Malang University, Malang, Indonesia \\ Corresponding e-mail: yerry.soepriyanto.fip@um.ac.id
}

\begin{abstract}
This development aims to create a valid product maze game on Interactive WhiteBoard (IWB) for fine motor learning. Game maze is a game consisting of a path or a collection of roads that branch in order to achieve the goal by finding the right path. IWB use for projection game and place which user can interactive with it. IWB cheaper design by Johnny Chung Lee used for this development. There are ten steps that must be carried out referring to the model of the Borg and Gall, but based on certain considerations are not entirely done. The stages are research and information collecting, planning, preliminary form of product development, preliminary field test, and main product revision. The maze game on IWB has been validated by media experts and fine motor learning experts, with valid results. Nevertheless from the field trials revealed that the ease and smooth use of the tool into a separate note. This is due to infrared light cannot be caught by the sensor because it is blocked by students working on the board so that the interaction between games with IWB is disrupted and there is one child who have difficulty using an infrared pen.
\end{abstract}

Keywords: Game Maze, Interactive WhiteBoard, learning, fine motor

\section{INTRODUCTION}

According to gardner that An intelligence is the ability to solve problems, or to create products, that are valued within one or more cultural settings[1]. These intelligences are linguistic intelligence ("word smart"), Logical-mathematical intelligence ("number/reasoning smart"), Spatial intelligence ("picture smart"), Bodily-Kinesthetic intelligence ("body smart"), Musical intelligence ("music smart"), Interpersonal intelligence ("people smart"), Intrapersonal intelligence ("self smart"), Naturalist intelligence ("nature smart"). Visual-spatial intelligent is the one of multiple intelligence that deals with spatial judgment and the ability to visualize with the mind's eye. Person who has visual spatial intelligence very aware of their environments. They like to draw, do jigsaw puzzle, read map. They can be taught through drawings, verbal and physical imagery. While Armstrong argues that spatial visual is the ability to visualize images in a mind [2]. This intelligence is used by the child to think creatively in the form of visualization and drawing to solve a problem or find an answer.

Playing a maze game challenges players solving problems by finding the pathway out of a narrow room or finding the direction of the end of some winding paths. Game maze is a game that hones spatial visual intelligence where one's ability to comprehend deeply the relationship between objects and space. Maze is usually in great physical shape and requires a large place or in early childhood education made of paper or cardboard in which contains narrow pathways. In general, maze games are performed in early childhood education with simple boards that are shaped in such a way and the characters are tailored to the theme. Therefore students tend to feel bored and do other things that are disruptive to the classroom atmosphere.

The product developed is a software maze game integrated with Interactive Whiteboard designed by Johny Chung Lee. Swan et al argues that an interactive whiteboard allows teachers and students to interact with content projected from a computer screen to the surface of the board. Whatever can be done virtually on a computer, it can also be done on a board surface. in his research revealed the advantages of interactive boards is the interaction with digital content that includes the manipulation of information with fingers and pens that make learning more active, kinesthetic, and interesting [3]. 
Fig. 1. Placement IWB device.

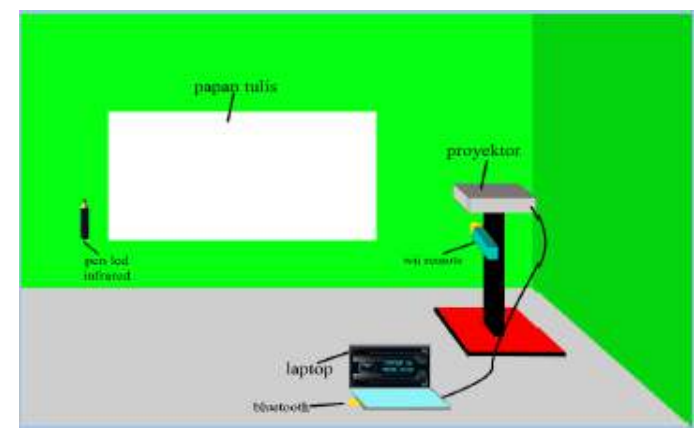

\section{THEORETICAL FOUNDATION}

\subsection{Interactive Whiteboard}

According to Miller \& Glover: The interactive whiteboard comprises a computer connected to the projector and a large touchscreen board that can display the projected image, the user can make direct input using a finger or a special pen so that objects around the board can be easily moved 'Drag and drop') or modified by teacher or student [4]. This technology combines an LCD projector and a computer screen with a board that can be touched to control as well as application programs that run on the operating system (Windows). Commercially available in various models of interactive touch board, one of which is SMARTboard which was very expensive for a school institution. In general, when buying these devices already provided the board, LCD projector, the connector is connected to a computer and software for controlling the interaction with the board and the application program used to run it.

For devices used IWB is a draft of Johnny Chung Lee is more affordable. The design started in 2008 , along with the many users with a gaming device Nintendo WII console. The game console device controllers are the Wiimote (Wireless Remote) receiving interaction via InfraRed receiver and sends a signal proceeds to other devices with Bluetooth. The draft consists of several key tools that white board (whiteboard), Wiimote, Bluetooth dongles, Infrared pen, projector, computer or similar Laptop/notebook, as well as controlling the interaction software installed on the computer. Placement of the primary device is shown in Figure 1 , which leads to the laid Wiimote whiteboard with InfraRed sensor (IR) facing the whiteboard. Bluetooth dongle is plugged into the USB port of a computer that already installed the software controlling the interaction and LCD Projector. For its IR pen is used as a tool for interaction with the whiteboard.

Overall costs are more than $\$ 150$ or Rp. 2.100.000, - (Rp. 14,000 / \$ 1) assuming the projector and the computer is already in the class as a standard learning facilities. To use the device controller software design of Johnny Chung Lee is free and open source. Thus this design is cheaper than the IWB mass-produced by the company's software developers.

\subsection{Maze Game}

Play is an intellectual activity engaged in for its own sake, with neither clearly recognizable functionalities nor immediate biological effects and related to exploratory processes that follow the exposure of the player to novel stimuli [6]. The definition of game is a set of activities involving one or more players. It has goals, constraints, payoffs and consequences[7]. A game is rule-guided and artificial in some respects. Finally, a game involves some aspect of competition, even if that competition is with oneself.

Games can be used for educational purposes, so the game is used as a tool to learn and acquire knowledge. Computer games can be characterised by six key structural elements which, when combined together, strongly engage the player. These elements are rules, conflict / competition / challenge / opposition, goals and objectives, interaction, outcomes and feedback also representation or story [8]. A key feature of educational games is the opportunity to apply subject matter knowledge in a new context. For example, the computer game Mineshaft requires the players to use fractions to retrieve a miner's ax that has fallen into the shaft [9].

A maze is a path or collection of paths, typically from an entrance to a goal. The word is used to refer both to branching tour puzzles through which the solver must find a route, and to simpler nonbranching ("unicursal") patterns that lead unambiguously through a convoluted layout to a goal. [10] Generally, Maze consist of pathways and walls, if the player touches the frame or outer edges of the level, then they lose and have to start the game over.

Finally, playing educational maze games is a tool for learning and acquiring knowledge by engaging in intellectual activity to find the path to reach the target with the rule of not touching the 
walls around the road since passing through. In general, the maze game is physical, but it can be designed and developed in the form of computer games.

\subsection{Fine Motor Learning}

There are two types of motor that need to be developed in human life that is fine motor and gross motor, which underlies from other development [11]. The development can be done by playing, because by playing involving motor movement. Playing provides a vast opportunity to move, a learning experience to discover, motor sensory activity that includes large and small muscles, making it possible to meet perceptual motor development.

Developing fine motor after gross motor, due to perform fine motor movements needed control of the smooth muscles in the hands, especially the fingers needed to perform drawing, sticking, cutting, shading and so forth. In Hurlock's opinion, fine motor is a movement associated with the smooth muscles of a particular body part, its development being influenced by the opportunity to learn and practice [12]. Magill also stated that the fine motor skills as a movement that requires the muscles of small size to achieve specific goals [13]. The control can be either hand-eye coordination or movements that involve the hands and fingers to work with high precision.

Finally, fine motor skills such as cutting, sticking, playing puzzles, making collages, playing with plastic, coloring, shading and others, are skills that require finger dexterity, high levels of accuracy and involve eye and finger coordination. The development is needed to experience the opportunity to learn and practice in order to achieve competence in aspects of fine motor development

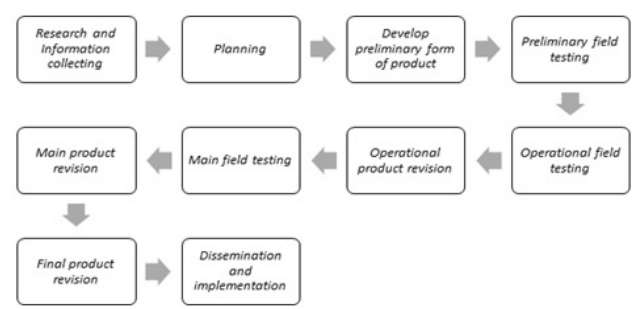

Fig. 2. Development Models stage adapted from Borg and Gall

\section{METHOD}

A research and development model of Borg and Gall that has been adapted to obtain seven stages of research and development. Ten stages are shown in Figure 2 consisting of (1) Research and information collecting; (2) Planning; (3) Development Primary Form of Product; (4) Preliminary Field Test; (5) Main Product Revision; (6) Main Field Testing; (7) Operational Product Revision; (8) Operational Field Testing; (9) Final Product Revision; (10) Dissemination and implementation. Based on certain considerations, it is not all stage do. Stage that is carried out only five stages only (1) Research and information collecting; (2) Planning; (3) Development Primary Form of Product; (4) Preliminary Field Test; (5) Main Product Revision. This is due to consideration of time and cost required large enough, so only limited prototype that has been tested in small scale.

Research and information collecting stage involve literature survey, class observation, and preparing state report since observation or need assessment. In planning stage, developer must formulate goals, evaluations and analysis. Developing preliminary product, product manual, instruction of use or tutorial using product and developing validation test instrument are activity on stage Development primary form of product. On stage preliminary field test, the activity will be evaluation from judgment expert and trial on field. The last stage is the main product revision which the product will be repaired based on the advice of judgment expert and field trials.

Validation of the developed product should be done by media experts and material experts to determine the feasibility of the media. Media experts are selected from lecturers of educational technology who understand the media of learning. Validation of the material experts selected from the school institution of early childhood education, in this case is the teacher who teaches it. Last validation is from experts in the field of fine motor learning in early childhood. For this validation does not use a questionnaire but uses an open and unstructured interview. This is done to obtain as much information about the media developed without limiting answers like other experts. Based on the results from the validation of media experts and material experts obtained input used as material revision products.

After product revision, field trials are conducted. Maze Game on an interactive board is tested on students at Kalikejambon Tembelang Jombang 
Kindergarten. There are 20 kindergarten students participating in the field trial and two teachers. From field trials we get an overview of the game maze when used in early childhood learning activities.

This development product is an interactive whiteboard prototype. The required tools are computer or laptop, with minimum computer specification or laptop pentium 4 using Windows 7 operating system, 1 GB RAM and CD-ROM in it. LCD Projector, WII Remote, and IR pen equipped with infrared LED sensor. Maze game application software development with software rapid application development (RAD) which supported by graphics, image and audio processing software.

\section{RESULT AND DISCUSSION}

Validation is carried out to provide information about products developed especially on media feasibility when used for learning. There are three feasibility test that is feasibility toward developed media, feasibility to the submitted material and media feasibility test in fine motor study. Feasibility test is delivered in the form of a questionnaire and accompanied by demonstration of utilization.

A questionnaire survey media expert consists of aspects of clarity, attractiveness, ease, interactivity and fluency. The test results of media experts stated that the media in the category is valid with the average percentage of $93.75 \%$ and can be used for learning, although the aspect of ease and smoothness cannot get a better score among others.

The material expert questionnaire consists of material clarity, material conformity, and material depth. The result is the media expressed in a valid category with an average percentage of $92.5 \%$ and can be used for fine motor learning. These results are not good as media experts, this is because the material presented is limited to fine motor aspects. The same notes conveyed by the expert with the media expert that ease and fluency are things to be considered in the utilization of this learning media

To test the feasibility of media in learning fine motor unstructured interviews conducted by the expert in the field of fine motor learning, early childhood education. The results show that the game maze developed is interesting and certainly motivates the child to learn and the child is invited to solve the problem by playing a fun. Nonetheless maze game as a whole does not cover aspects of the attainment of fine motor skills. This is due to children who learn fine motor with maze game on the Interactive Whiteboard only seek and follow the path alone with the rules is not allowed to touch the walls. The movement follows the plot was merely move the arm even though there is an element of accuracy in it. According to the expert judgment, this media can be used for learning and practicing fine motor coordination only on the part of the eye and the hand or eye-hand coordination competencies.

Based on field trial when the students performing activities using maze game in kindergarten Kalikejambon Tembelang Jombang during an hour of study. Evidence shows that students are very enthusiastic, interested to try and observe his friends in interacting with the media and even give direction to his friend to move to the right path to the target. This indicates that the media can be used to study individually or in groups even collaborate or cooperative. Although 20 students want to try the game maze, they patiently wait their turn alternately.

Nevertheless there are some notes in the trial that have been done, especially on the smooth use and ease in interacting with the device. There is even a child who dare not try to see his friend is always guided researchers in the move and then feel frustation with that. This is due to Infra Red LED and IR detector unstable power supply along with IR detector and IR transmitter is blocked by students who are using it.

The teacher's response during the test shows that there is a possibility that teachers can not afford to prepare and install the device, because there are many things to do before the lesson begins. For that it should be given training in installing it, and also training in using interactive whiteboard for learning purposes in the classroom

\section{CONCLUSION}

Development of maze games for fine motor learning can provide innovation in teachers while learning in the classroom. Students in early childhood education interested in playing game maze proven on field trials demonstrated high attractiveness, enthusiasm and cooperation among students. Although there is one student who has difficulty in interacting with game maze, thus causing other students not dare to try. Early childhood motor education specialists give their own notes in the aspect of competence that is not achieved as a whole fine motor, only in eye and hand coordination only. Similarly, the ease and fluency of the use of pen Infra Red be a note from media experts and material experts. 


\section{REFERENCES}

[1] H. Gardner, Frames of Mind. New York. Basic Books. 2011.

[2] T. Armstrong, Multiple intelligences in the classroom, $3^{\text {rd }}$ edition. Alexandria, VA. ASCD. 2009

[3] K. Swan, A. Kratcoski, J. Schenker, and M. Hooft, (2010). "Interactive whiteboards and student achievement," in Interactive Whiteboard for Education: Theory, Research and Practice. New York, 2010, pp. 131-143.

[4] D. Miller, and D. Glover, "Interactive whiteboard: a literature survey," in Interactive Whiteboard for Education: Theory, Research and Practice. New York, 2010, pp. 1-19.

[5] J. Chung-Lee, http://johnnylee.net/projects/wii. Retrieved May 23, 2011.

[6] C. Fabricatore, Learning and videogames: an unexploited synergy. At www.learndev.org/d1/FabricatoreAECT2000.p df, accessed 14 April 2016

[7] J. V. Dempsey, B. A. Lucassen, L. L. Haynes, and M. S. Casey, Instructional applications of computer games. Paper presented to the American Educational Research Association, 8-12 April 1996, New York. ERIC Document Reproduction Service No. ED 394500.

[8] M. Prensky, Digital game-based learning. New York: McGraw-Hill. 2001

[9] L. P. Rieber, "Seriously considering play: Designing interactive learning environments based on the blending of microworlds, simulations, and games," Educational Technology, Research, and Development, vol $44 \quad$ (2), 43-58. 1996. https://en.wikipedia.org/wiki/Maze

[10]C. E. Catron, and J. Allen, Early childhood curriculum: A creative play model, 4 th Edition. Upper Saddle River, NJ: Pearson. 2008.

[11]E. B. Hurlock, Child development. Tokyo. McGraw-Hill. 1956.

[12]R.A. Magill, Motor learning and control: Concepts and applications. Boston. McGrawHill. 2004.

[13] W. Borg, and M. Gall, Educational research: an introduction. New York: Longman Inc. 1983 